\title{
LA EJECUCIÓN PROVISIONAL DE LA SENTENCIA EN LOS REGÍMENES PROCESALES DE LA NACIÓN Y LAS PROVINCIAS DEL NORDESTE
}

Marcelo S. Midón ${ }^{1}$

\section{Ejecución provisional. Concepto}

Ejecución provisional, dice Gozaíni, es la facultad que tiene la parte para requerir el cumplimiento de una sentencia condenatoria que aún no se encuentra consentida. Su razón de ser, agrega, reposa en la celeridad procesal y en la satisfacción inmediata que consigue quien ha logrado el reconocimiento de sus derechos dictada la sentencia favorable. ${ }^{2}$

A su turno, para Juan Monroy Gálvez, la actuación inmediata de la sentencia impugnada es el instituto procesal, especie de tutela anticipada, por medio del cual se concede a la parte que ha obtenido una decisión favorable en primer grado el derecho a la actuación de la decisión que lo favorece, con prescindencia de que la resolución vaya a estar o esté recurrida por la parte perdedora, y que desarrolla su ámbito de aplicabilidad en la zona de intersección entre dos intereses; por un lado, el riesgo que debe soportar el litigante inicialmente vencedor, quien debe hacer frente a la demora del segundo grado y, por otro, el interés de la jurisdicción de no conceder al vencedor inicial más de lo que corresponda recibir. ${ }^{3}$

\section{Antecedentes}

\section{Ley de Enjuiciamiento Española}

Cuyo Libro III, Título II, arts. 524 a 537 reglamentan "la ejecución provisional" respecto de sentencias condenatorias del siguiente modo.

${ }^{1}$ Profesor de Derecho Procesal Civil y Comercial de la Facultad de Derecho y Ciencias Sociales y Políticas de la UNNE.

${ }^{2}$ Gozaíni, Osvaldo, La ejecución provisional en el proceso civil, en Revista Peruana de Derecho Procesal, N III, Lima, 1998, p. 81.

${ }^{3}$ Monroy Gálvez, Juan, La actuación de la sentencia impugnada, en Revista Iberoamericana de Derecho Procesal, Año I, Nº 1, Bs. As., 2002, p. 258. 
a) Requisitos de promoción. La ejecución podrá pedirse en cualquier momento desde la notificación de la sentencia. Formulada la misma, el tribunal la despachará salvo que se trate de sentencias excluidas (enumeradas por el artículo $525)^{4}$ o de aquellas que no contuvieren pronunciamiento de condena a favor del solicitante (art. 527), y sin prestación de fianza (art. 526).

b) Oposición. Motivos que la habilitan. Oportunidad y traslado. Según los artículos 528 y 529, LEE, el ejecutado sólo podrá oponerse a la ejecución provisional después de haber sido ésta despachada, y únicamente con invocación de las siguientes causas:

- Haberse despachado la ejecución con infracción del artículo 527 (tratándose de sentencias excluidas o de aquellas que no contuvieren pronunciamiento de condena);

- Sí la sentencia fuese de condena no dineraria, resultara imposible o de extrema dificultad, atento la naturaleza de las actuaciones, restaurar la situación anterior a la ejecución o compensar al ejecutado mediante el resarcimiento de los daños y perjuicios que le causaren, si la sentencia fuese revocada;

- Si la sentencia fuese de condena dineraria, el ejecutado sólo podrá oponerse cuando entienda que dichas actuaciones causarán una situación imposible de restaurar o de compensar económicamente a través del resarcimiento de los daños y perjuicios que se le causaren, si aquella sentencia fuese revocada.

Al formular la oposición, el ejecutado deberá indicar otras medidas o actuaciones ejecutivas que sean posibles y no provoquen situaciones similares a las que causaría, en su opinión, la actuación o medida a la que se opone, así como ofrecer caución suficiente para responder por la demora de la ejecución, si las medidas alternativas no fuesen aceptadas por el tribunal. Si el ejecutado no indicara medidas alternativas ni ofreciese prestar caución suficiente, no procederá en ningún caso la oposición, sin recurso alguno.

La oposición deberá formalizarse en el perentorio plazo de cinco días a computar desde la notificación del auto por el que se despacha la ejecución. Y de

${ }^{4}$ Según el artículo 525, LEE, las "sentencias no provisionalmente ejecutables" son: 1. Las dictadas en los procesos sobre paternidad, maternidad, filiación, nulidad de matrimonio, separación y divorcio, capacidad y estado civil y derechos honoríficos, salvo los pronunciamientos que regulen las obligaciones y relaciones patrimoniales relacionados con lo que sea objeto principal del proceso; 2. Las que condenen a emitir una declaración de voluntad; 3. Las que declaren la nulidad o caducidad de títulos de propiedad industrial. 
él se dará traslado al ejecutante, por igual plazo, para que manifieste y acredite lo que considere conveniente.

c) Resolución. Que se dictará después de cumplido el trámite de la sustanciación.

Si se estimase fundada la oposición, se dejará sin efecto el trámite de ejecución, ordenándose el levantamiento de los embargos y demás medidas de garantía que se hubieren adoptado. Empero, si la oposición se hubiera formulado en caso de ejecución de condena no dineraria, y el tribunal estimase que sería imposible o extremadamente difícil restaurar la situación anterior a la ejecución, dictará auto dejando sin efecto la ejecución, pero subsistirán los embargos y demás medidas de garantía adoptadas (art. 530, incs. $1^{\circ}$ y $2^{\circ}$ ).

Siendo dineraria la condena, el tribunal únicamente podrá estimar la oposición:

1) Si considerara posibles las alternativas indicadas por el ejecutado o estimase suficiente la caución por éste ofrecida para responder por la demora de la ejecución, y;

2) Que concurre en el caso absoluta imposibilidad de restaurar la situación anterior a la ejecución o de compensar económicamente al ejecutado mediante ulterior resarcimiento de los daños y perjuicios, si la sentencia fuese revocada (art. 530, inc $3^{\circ}$ ).

Contra el auto que decida sobre la oposición a la ejecución provisional o medidas ejecutivas concretas no habrá recurso alguno (art. 530, inc. $4^{\circ}$ ).

d) Suspensión de la ejecución provisional. Se suspenderá la ejecución provisoria de la sentencia de condena al pago de cantidades líquidas de dinero cuando el ejecutado pusiere a disposición del juzgado, para su entrega al ejecutante, la cantidad a la que hubiere sido condenado, más los intereses correspondientes y las costas (art. 531). 


\section{Anteproyecto de Código Procesal Civil Modelo para Iberoamérica}

Que incorporó la figura de la ejecución provisional en su artículo 230, sujetándola al siguiente procedimiento:

a) Requisitos de promoción: La solicitud deberá formalizarse dentro del plazo de seis días a contar del siguiente a su notificación, previa garantía de satisfacción del tribunal para responder, en su caso, por todos los gastos judiciales, daños y perjuicios que pudiere ocasionar a la parte contraria (art. 230 , inc. $1^{\circ}$ ).

b) Suspensión de la ejecución provisional: El ejecutado podrá solicitar la suspensión de la ejecución provisoria por causarle perjuicio; circunstancia que el tribunal apreciará discrecionalmente. Si estimare que existe esa posibilidad, exigirá al condenado que preste garantía bastante para asegurar, en todo caso, lo que ha de ser objeto de la ejecución más los intereses y las costas que se pudieran irrogar (art. 230, inc. $2^{\circ}$ ).

Si bien la norma no lo contempla de modo expreso, interpretamos que dicho pedido de suspensión tramitará incidentalmente de manera, pues, que el dictado de la resolución que recaiga sobre el mérito de la misma será posterior de otorgar traslado al ejecutante.

c) Trámite posterior: Según el artículo 321 , inc. $1^{\circ}$, la ejecución provisoria y la definitiva se realizarán por igual procedimiento (el que a su vez está regulado por el Libro II, Título V, "Procesos de ejecución").

Si la sentencia de segunda instancia confirmare la de primera, declarará al mismo tiempo, definitiva la ejecución provisoria; igual sucederá en el recurso de casación. Si la revocare, decretará que vuelvan las cosas a su estado anterior más los daños y perjuicios que correspondieren; y de no ser ello posible, se abonarán los daños y perjuicios que hubiere causado la ejecución provisoria. El reclamo del pago y la liquidación de los daños y perjuicios tramitarán por vía incidental (inc. $2^{\circ}$ ). 


\section{Derecho comparado}

\section{Asimismo, la modalidad ha sido programada, entre otros, por los códigos procesales civiles de Alemania, ${ }^{5}$ Brasil $^{6}{ }^{6}$ Francia, ${ }^{7}$ Italia ${ }^{8}$ y Uruguay. ${ }^{9}$}

${ }^{5}$ El Código Procesal Civil de Alemania (ZPO), art. 704, prevé que "La ejecución tiene lugar sobre la base de sentencias definitivas firmes, o que hayan sido declaradas por provisoriamente ejecutables". A su turno, el art. 708 enumera en once incisos cuales son las sentencias provisoriamente ejecutables sin otorgamiento de caución: así, verbigracia, las pronunciadas sobre la base de allanamiento o desistimiento; las dictadas en los procesos documentales, cambiarios o de cheques; aquellas mediante las cuales se rechacen o se revoquen embargos o medidas provisorias; las dictadas en procesos entre el locador y el locatario y/o el sublocatario de inmueble para vivienda; las que declaren la obligación de manutención; las de restitución de la posesión, eliminación o cese de alguna turbación a esta; las dictadas por la alzada en cuestiones litigiosas patrimoniales, etcétera. El art. 709, regula cuales son las sentencias provisionalmente ejecutables contra otorgamiento de caución. Y el art. 712 establece que el deudor, en caso de que la ejecución le ocasione un perjuicio irreparable, podrá solicitar al tribunal que se evite la ejecución mediante el otorgamiento de una caución o consignación.

${ }^{6} \mathrm{El}$ ordenamiento procesal brasileño regula como principio el efecto suspensivo del recurso de apelación con que se ataca la sentencia, aunque el artículo 520 establece por excepción los casos en los que la apelación no tendrá efecto suspensivo, a saber: las apelaciones que se interpongan contra la sentencia que homologa la división o la demarcación; condena a prestación de alimentos; resuelve la liquidación de la sentencia; decide el proceso cautelar, rechaza liminarmente embargos a la ejecución o los resuelve como improcedentes.

La ejecución provisoria de la sentencia se hará (dice el art. 588) del mismo modo que la definitiva, observando los siguientes principios: 1 . Corre por cuenta y responsabilidad del acreedor, quien deberá prestar caución obligándose a reparar los daños y perjuicios causados al deudor; 2. No alcanza a los actos que importen transferencia de dominio, ni permite, sin caución idónea, la entrega de depósitos en dinero; 3. Queda sin efecto si sobreviene sentencia que modifique o anule la que fue objeto de ejecución, restituyéndose las cosas a su estado anterior.

${ }^{7}$ El Código Procesal Civil de Francia reglamenta la modalidad de ejecución provisional en sus artículos 514 a 526. Según esta normativa la actuación anticipada puede ser promovida sobre la base de previsión legal establecida para algunos casos; en otros corresponde ser pedida por el interesado e, inclusive, determinada de oficio si el juez la considerara necesaria y careciere de prohibición legal. Asimismo, la parte vencida podrá impedir la ejecución provisoria si ofrece garantía suficiente; opción esta que no se da en procesos de alimentos o de reparación indemnizatoria. Véase, Monroy Gálvez, Juan, La actuación de la sentencia impugnada, en Revista Iberoamericana de Derecho Procesal, ob. cit., p. 266.

${ }^{8}$ En Italia, el artículo 377 del Código Procesal Civil establece que la ejecución de la sentencia no se suspende por efecto de la impugnación, salvo hipótesis de excepción. La ejecución provisional de la sentencia de primera instancia se consagra como regla general (art. 282), consolidándose así un reclamo de la doctrina que veía en el recurso de apelación un abuso procesal. Sin embargo, el art. 283 prevé que "el juez de apelación a instancia de parte, propuesta en la impugnación principal o incidental, cuando concurran graves motivos, debe suspender total o parcialmente la eficacia ejecutiva o de la ejecución de la sentencia impugnada".

${ }^{9}$ En la República Oriental del Uruguay la ejecución provisoria se presta a pedido de parte y otorgando ésta garantía por las pérdidas y daños que podría causar una revocatoria a la parte perdedora. En un principio, el Código General del Proceso le otorgaba al juez la facultad de conceder o no la ejecución provisoria atendiendo a la existencia o no de peligro de frustración; sin embargo, la ley 16.699, que modificó algunos aspectos del Código, eliminó este requisito (art. 260.1). Asimismo, la norma concede al vencido el derecho de oponerse si acredita que la ejecución le producirá perjuicios difíciles de ser reparados, siempre, además, que otorgue garantía (art. 260.3). 


\section{La ejecución provisional en el régimen de los CPCC de la Nación y de las provincias del Nordeste}

\section{Casos en que procede}

En nuestro país, particularmente en el sistema del Código Procesal Civil y Comercial de la Nación y de sus pares vigentes en las provincias del nordeste, que siguieron sus lineamientos, la ejecución provisional de la sentencia definitiva sometida a recurso ha sido prevista de manera taxativa, frente a situaciones excepcionales, a saber:

a) Procesos sumarisimos. Incluidos los interdictos; la sentencia definitiva y sin necesidad de prestar fianza; salvo cuando su cumplimiento pudiese ocasionar perjuicio irreparable (CPCCN, art. 498, inc. 6; Corrientes, art. 498, inc. 5; Chaco, art. 475, inc. 7; Misiones, art. 466, inc. 5, $2^{\circ}$ párrafo; Formosa, art. 495, inc. 6).

b) Juicio ejecutivo. La sentencia de remate, cuando el ejecutante diere fianza de responder de lo que percibiere si el fallo fuese revocado (CPCC Nación y Corrientes, arts. 555; Chaco, art. 553; Misiones, art. 524; Formosa, art. 552).

c) Ejecución de sentencias. La resolución que desestime las excepciones, mandando llevar adelante la ejecución, a condición que el interesado diere fianza o caución suficiente (CPCC Nación y Corrientes, arts. 509; Chaco, art. 505; Misiones, art. 477; Formosa, art. 506).

d) Juicio de alimentos. La sentencia definitiva cuando es a favor del actor alimentado y sin necesidad de prestar caución (CPCC Nación y Corrientes, art. 647; CPCC Misiones, art. 625).

e) Sentencia de cámara confirmatoria de la dictada en primera instancia. A condición que el interesado en la ejecución preste fianza de responder por lo percibido si el fallo fuese revocado (CPCCN, art. 258; Misiones, art. 294).

f) Medida autosatisfactiva. Sí bien el rito federal no regula sobre la figura, en todos aquellos que sí la legislan (CPCC Corrientes, art. 789; Chaco, art. 253, inc. e); Misiones, art. 683; Formosa, art. 232 bis, inc. e), la ejecución provisoria ha sido prevista para la hipótesis en que se apelara la sentencia que otorgó la medida, ora que el fallo haya sido pronunciado in audita pars o previa breve sustanciación.

En punto a la fianza, por principio, la ejecución de una medida autosatisfactiva depende de la prestación de contracautela. Empero, las fuentes autorizan a prescindir de su imposición, según las circunstancias del caso, especialmente 
cuando haya mediado una sustanciación previa a su despacho.

En efecto, según los Códigos Procesales Civiles de Corrientes (art. 785); Chaco (art. 253) Misiones (art. 636) y Formosa (art. 232 bis) el juez "podrá exigir" la prestación de cautela. Se trata, entonces, de una facultad discrecional del magistrado; quien, de frente a las circunstancias del caso (tomando en cuenta, verbigracia, la naturaleza de la pretensión, la inminencia del perjuicio que pueda causar el hecho denunciado, etcétera), decidirá si exigirá contracautela o no, y de qué tipo (a cuyo efecto deberá meritar, por ejemplo, los medios económicos del actor, la magnitud de los daños a generarse si la medida fuera pedida sin derecho, etcétera).

g) Procesos monitorios. Únicamente previsto por el código de rito de la provincia del Chaco, la resolución que rechazó in limine la oposición a la sentencia monitoria, a condición que el ejecutante diere fianza de responder por lo que percibiere (art. 479).

h) Chaco. Ejecución provisional. A pedido del interesado, cuando exista peligro de frustración del derecho reconocido por la sentencia, derivado de la demora en el trámite de la segunda instancia, tratándose de prestaciones de naturaleza patrimonial. Para ello deberá, previamente, prestarse caución suficiente que fijará el a quo, teniendo en cuenta los eventuales daños y perjuicios que se sigan de la misma (art. 282).

\section{Presupuestos}

Los requisitos que condicionan el excepcional procedimiento de la ejecución provisional son los siguientes:

a) Pendencia de recurso. La sentencia cuya ejecución provisional se pretenda debe hallarse recurrida y la vía de gravamen articulada asimismo pendiente de resolución.

De pura lógica: si el fallo se encuentra consentido (por haberse dejado transcurrir infructuosamente el plazo para recurrirlo) o ejecutoriado (por haberse agotado a su respecto todas las instancias recursivas garantizadas por el ordenamiento), entonces habrá adquirido atributo de cosa juzgada y, por consiguiente, la ejecución que de él se pretenda tendrá carácter definitivo y no meramente provisorio.

Cabe señalar, sin embargo, que algunos autores admiten el que pueda habilitarse la ejecución a partir del dictado de la resolución y sin tener que esperar la 
interposición del recurso. Así, para Osvaldo Gozaíni, este criterio parece aceptable en la medida que el órgano jurisdiccional asuma la responsabilidad de resolver rápidamente los actos procesales necesarios para dar vida a la ejecución en forma inmediata; de otro modo, es posible que se constituya una fianza innecesaria, o se provoque una actividad judicial que prontamente perdería virtualidad de consentirse la sentencia. ${ }^{10}$

b) Que la ley programe la potencial ejecución. Fuera de los casos taxativamente contemplados por la ley, la ejecución transitoria de la sentencia recurrida deviene absolutamente improcedente. Más todavía en los sistemas adjetivos vigentes en nuestro país, en virtud de los cuales la mera interposición de los recursos de apelación y extraordinario provoca — regularmente - el efecto suspensivo.

Tanto es así que acordar venia judicial a la actividad tendente a ejecutar provisoriamente la sentencia recurrida (las veces en que dicha impugnación tenga efecto suspensivo) constituiría un exceso jurisdiccional susceptible de anularse vía recurso de atentado o por innovación.

c) Que se trate de sentencia condenatoria. De manera, pues, que por principio, los fallos de carácter meramente declarativo o constitutivo, para ser ejecutables, deberían aguardar adquirir la plena eficacia que les confiere la autoridad de cosa juzgada.

Temperamento éste que se ve reflejado en el Código General del Proceso uruguayo (art. 260.1) y su par vigente en la República Federativa de Brasil (art. 520). Asimismo, primó en ocasión de la última reforma a la Ley de Enjuiciamiento Española (Ley 1/2000) ${ }^{11}$ y en oportunidad de elaborarse el Anteproyecto de Código Procesal Civil Modelo para Iberoamérica (véase artículo 230 , antes transcripto).

d) Iniciativa de parte. De perogrullo, por la vigencia del sistema dispositivo, que enerva la posibilidad de actuación oficiosa del órgano judicial tendente a promover la ejecución de la sentencia. La excepción, dicen Gozaíni y Monroy

${ }^{10}$ Gozaíni, Osvaldo, La ejecución provisional en el proceso civil, en Revista Peruana de Derecho Procesal, ob. cit., p. 93.

${ }^{11}$ La Ley de Enjuiciamiento Española, después de establecer en su artículo 524 que la ejecución provisional ha sido programada respecto de sentencias de condena (aserción que es reiterada por el art. 527), enumera en su artículo 525 cuales son las "sentencias no provisionalmente ejecutables", a saber: 1. Las dictadas en los procesos sobre paternidad, maternidad, filiación, nulidad de matrimonio, separación y divorcio, capacidad y estado civil y derechos honoríficos, salvo los pronunciamientos que regulen las obligaciones y relaciones patrimoniales relacionados con lo que sea objeto principal del proceso; 2 . Las que condenen a emitir una declaración de voluntad; 3 . Las que declaren la nulidad o caducidad de títulos de propiedad industrial. 
Gálvez, proviene del derecho francés que admite la procedencia del mecanismo dispuesto de oficio. ${ }^{12}$

Cabe aclarar, sin embargo, que la ley adjetiva francesa habilita que el juez, ex officio, declare si la resolución será susceptible (o no) de ejecutarse provisionalmente. Empero, y de allí que no represente - a nuestro entender - una verdadera excepción, el inicio del procedimiento destinado a instrumentar el cumplimiento del fallo condenatorio siempre dependerá del estímulo del justiciable interesado.

e) Fianza. Las veces que la ley así lo requiera. ${ }^{13}$ Que lógicamente dará el ejecutante para responder por los perjuicios irrogados en caso de que la sentencia resulte revocada. Ora que la preste él mismo, ora que la garantía sea brindada por un tercero.

\section{Procedimiento}

La ejecución provisional de la sentencia sujeta a recurso, condicionada por la verificación de alguna hipótesis taxativa contemplada por la ley adjetiva, se realizará conforme al procedimiento previsto para la ejecución de sentencias (CPCC Nación y Corrientes, arts. 499 y siguientes; Chaco, art. 495; Misiones, art. 467; Formosa, art. 496).

El título ejecutorio consistirá, en tales casos, en un testimonio que deberá expresar que ha recaído sentencia respecto del rubro que se pretenda ejecutar, pese haber sido recurrida la misma.

\section{Suspensión de la ejecución}

Cuando la ley así lo permita, el ejecutado podrá solicitar la suspensión de la ejecución provisional que lo afectare, en la medida que acredite la posibilidad de sufrir un perjuicio de difícil o de imposible reparación, previo ofrecimiento y prestación de contra cautela suficiente.

Verbigracia, tratándose de la ejecución de la sentencia del proceso sumarísimo (CPCC Nación, art. 498, inc. 6; Corrientes, art. 498, inc. 5; Chaco, art.

${ }^{12}$ Gozaíni, Osvaldo, La ejecución provisional en el proceso civil, en Revista Peruana de Derecho Procesal, ob. cit., p. 93; Monroy Gálvez, Juan, La actuación de la sentencia impugnada, en Revista Iberoamericana de Derecho Procesal, ob. cit., p. 266.

${ }^{13}$ Adviértase, sin ir más lejos, que la Nueva Ley de Enjuiciamiento Española (Ley 1/2000) eliminó como requisito previo de la ejecución provisional la prestación de fianza. Y que el Código Procesal Civil Alemán (ZPO), artículo 708, enumera en once incisos un generoso abanico de sentencias cuya ejecución provisional podrá llevarse adelante sin necesidad de dar caución. 
475, inc. 7; Misiones, art. 466, inc. 5, $2^{\circ}$ párrafo; Formosa, art. 495, inc. 6 ) y de la que otorgó medida auto satisfactiva (CPCC Corrientes, art. 788; Chaco, art. 253, último párrafo; Misiones, art. 639; Formosa, art. 232 bis, último párrafo). 